\title{
STUDI PERBAIKAN KUALITAS TEGANGAN DAN RUGI-RUGI DAYA PADA PENYULANG KULIM DAN JELUTUNG DENGAN MENGGUNAKAN APLIKASI ETAP 12.6
}

\author{
R.M. Edy Suherman ${ }^{1}$, Marliyus Sunarhati ${ }^{2}$ \\ Redisuherman67@gmail.com \\ ${ }^{1 \& 2}$ Dosen Tetap Yayasan pada Program Studi Teknik Elektro \\ Fakultas Teknik Universitas Palembang
}

\begin{abstract}
ABSTRAK
Suatu sistem tenaga listrik yang baik harus memiliki nilai tegangan yang tidak melebihi batas toleransi serta rugi-rugi daya yang kecil. Batas toleransi yang diperbolehkan untuk suatu nilai tegangan $\pm 5 \%$ dari nilai nominalnya. Nilai tegangan yang konstan akan mengoptimalkan unjuk kerja dari peralatan listrik yang digunakan oleh konsumen. Sedangkan rugi-rugi daya yang kecil akan menjaga pasokan daya listrik sesuai dengan kebutuhan konsumen, serta dapat mengurangi kerugian financial yang terjadi selama proses transmisi dan distribusi.Perbaikan dengan penggantian kabel pada penyulang Kulim dan Jelutung menghasilkan pengurangan rugi-rugi daya paling besar yaitu sebesar $0,133 \%$ dan 0,014 Metode penggantian kabel tersebut juga memperbaiki tegangan pada kedua penyulang. Dimana tegangan terendah di sisi tegangan menengah dan rendah dari penyulang Kulim setelah penggantian kabel adalah $0,83 \%$ dan $0,008 \%$ dari tegangan nominal. Sedangkan tegangan terendah di sisi tegangan menengah dan rendah dari penyulang Jelutung adalah $0,1333 \%$ dan $3,43 \%$ dari tegangan nominal.
\end{abstract}

Kata Kunci :Program ETAP, Kabel, Daya, Tegangan

\section{PENDAHULUAN}

\subsection{Latar belakang}

Suatu sistem tenaga listrik yang baik harus memiliki nilai tegangan yang tidak melebihi batas toleransi serta rugi-rugi daya yang kecil. Batas toleransi yang diperbolehkan untuk suatu nilai tegangan $\pm 5 \%$ dari nilai nominalnya. Nilai tegangan yang konstan akan mengoptimalkan unjuk kerja dari peralatan listrik yang digunakan oleh konsumen. Sedangkan rugi-rugi daya yang kecil akan menjaga pasokan daya listrik sesuai dengan kebutuhan konsumen, serta dapat mengurangi kerugian financial yang terjadi selama proses transmisi dan distribusi.

\subsection{Tujuan Penelitian}

Penelitian ini bertujuan untuk memberikan solusi terbaik dalam proses perbaikan tegangan dan rugi-rugi daya pada jaringan distribusi. Sehingga dengan melakukan proses perbaikan tersebut akan dapat menjaga tegangan tetap bernilai konstan serta dapat mengurangi rugi-rugi daya yang terjadi..

\subsection{Manfaat Penelitian}

Perbaikan kualitas tegangan pada jaringan distribusi dilakukan dengan melakukan penggantian kabel penyulang pada jaringan distribusi

\subsection{Ruang Lingkup}

Ruang lingkup pada penelitian ini, sebagai berikut:

1. Proses perbaikan tegangan hanya dilakukan pada sisi tegangan menegah dan rendah jaringan distribusi penyulang Kulim dan Jelutung.

2. Proses perbaikan disimulasikan menggunakan perangkat lunak ETAP 12.6

Studi Perbaikan Kualitas Tegangan dan Rugi-Rugi Daya Pada Penyulang Kulim dan Jelutung Dengan Menggunakan Aplikasi Etap 12.6

(R.M. Eddy Suherman, Marliyus Sunarhati) 


\section{TINJAUAN PUSTAKA}

\subsection{Sistem tenaga listrik}

Sistem tenaga listrik terdiri dari tiga komponen utama, yaitu pembangkitan tenaga listrik, transmisi dan distribusi. Pada pusat listrik dilakukan pembangkitan tenaga listrik dengan cara memanfaatkan generator.

Tenaga listrik yang telah dihasilkan pada pusat listrik akan ditransmisikan ke beban melalui saluran transmisi. Sebelum ditransmisikan, tegangan dinaikan dengan menggunakan transformator penaik tegangan (step-up) pada pusat listrik. Tegangan tersebut dinaikan ke level tegangan tinggi (antara $70 \mathrm{KV}$ sampai $150 \mathrm{KV}$ ) atau tegangan ekstra tinggi (diatas $150 \mathrm{KV}$ ). Tegangan menengah yang digunakan oleh PLN sebesar $20 \mathrm{KV}$. Pada level tegangan menengah ini, tenaga listrik dapat langsung digunakan oleh konsumen yang mempunyai daya tersambung besar seperti industri besar.

Setelah tenaga listrik disalurkan melalui jaringan distribusi primer, kemudian tegangan diturunkan pada gardu-gardu distribusi menjadi tegangan rendah 380/220 V yang kemudian disalurkan ke rumah-rumah pelanggan dengan menggunakan jaringan tegangan rendah, Gambar 2.1 menunjukkan diagram satu garis sistem tenaga listrik.

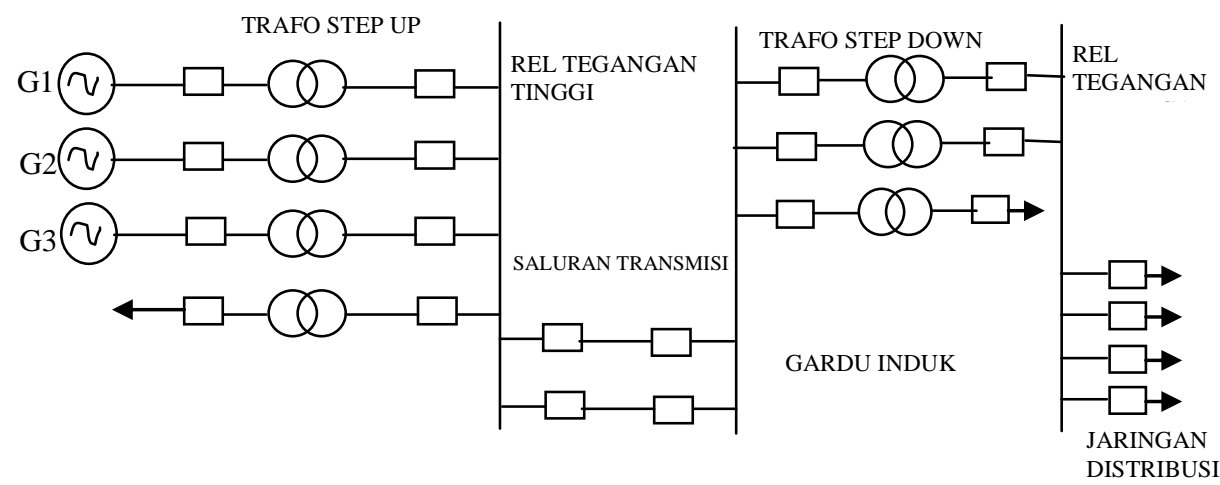

Gambar 2.1. Diagram satu garis sistem tenaga listrik

\subsection{Jatuh tegangan}

Penurunan persamaan jatuh tegangan dapat ditentukan dari gambar diagram fasor transmisi daya pada gambar 2.5

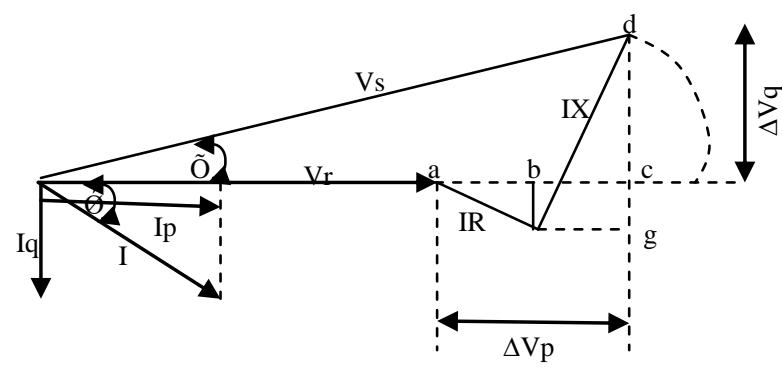

Gambar 2.5 diagram fasor transmisi daya ke beban seri

Umumnya beban yang terdapat pada sistem tenaga listrik bersifat resistif-induktif. Beban tersebut akan menyerap daya aktif dan daya reaktif yang dihasilkan oleh generator. Penyerapan daya reaktif yang diakibatkan oleh beban induktif akan menyebabkan timbulnya jatuh tegangan pada 
tegangan yang disuplai generator. Akibatnya nilai tegangan di sisi penerima akan berbeda dengan nilai tegangan di sisi pengirim. Persamaan jatuh tegangan dapat dilihat pada persamaan berikut :

$\mathrm{VS}^{2}=\left(\mathrm{Vr}+\Delta \mathrm{V}_{\mathrm{p}}\right)^{2}+\left(\Delta \mathrm{V}_{\mathrm{q}}\right)^{2}$

Keterangan : $\mathrm{VS}=$ tegangan di sisi pengirim

Dimana:

$\mathrm{Vr}=$ tegangan di sisi penerima

$\Delta \mathrm{V}_{\mathrm{p}}=$ jatuh tegangan

$\Delta \mathrm{V}_{\mathrm{p}}=\mathrm{IR} \cos \theta+\mathrm{IX} \sin \theta$

Dan

$\Delta \mathrm{V}_{\mathrm{p}}=\mathrm{IX} \cos \theta-\mathrm{IR} \sin \theta$

Sehingga persamaan tegangan di sisi pengirim (VS) menjadi :

$\mathrm{Vs}^{2}=(\mathrm{Vr}+\mathrm{IR} \cos \theta+\mathrm{IX} \sin \theta)^{2}+(\mathrm{IX} \cos \theta-\mathrm{IR} \sin \theta)^{2}$

Karena nilai $\Delta \mathrm{V}_{\mathrm{q}}=\mathrm{IX} \cos \theta-\mathrm{IR} \sin \theta$ sangat kecil, maka nilai tersebut dapat diabaikan. Sehingga persamaan $\mathrm{Vs}^{2}$ menjadi :

$\mathrm{Vs}^{2}=\left(\mathrm{Vr}+\Delta \mathrm{V}_{\mathrm{q}}\right)^{2}$

$\Delta \mathrm{Vq}=\mathrm{IR} \cos \theta+\mathrm{IX} \sin \theta$

$\Delta \mathrm{Vq}=\mathrm{R} \frac{\mathrm{P}}{\mathrm{Vr}}+\mathrm{X} \frac{\mathrm{Q}}{\mathrm{Vr}}$

Keterangan : $\mathrm{R}=$ Resistansi saluran

$\mathrm{X}=$ Reaktansi saluran

$\mathrm{P}=$ Daya aktif yang dikirim ke beban

$\mathrm{Q}=$ Daya reaktif yang dikirim ke beban

Dari persamaan (2.7) terlihat, nilai jauh tegangan ditentukan oleh beberapa faktor, yaitu daya aktif $(\mathrm{P})$, resistansi dan reaktansi saluran (RdanX) serta daya reaktif $(\mathrm{Q})$. Pengaturan daya aktif erat kaitannya dengan pengaturan frekuensi sistem. Sedangkan pengaturan daya reaktif akan mempengaruhi nilai tegangan. Oleh karena itu dengan melakukan pengaturan nilai daya reaktif kita dapat mengatur nilai tegangan.

\subsection{Rugi-rugi saluran}

Pemilihan jenis kabel yang akan digunakan pada jaringan distribusi merupakan faktor penting yang harus diperhatikan dalam perencanaan dari suatu sistem tenaga listrik. Jenis kabel dengan nilai resistansi yang kecil akan dapat memperkecil rugi-rugi daya. Besar rugi-rugi daya pada jaringan distribusi dapat ditulis dengan persamaan berikut:

$$
\text { Loss }=3 \mathrm{X} \mathrm{I}^{2} \mathrm{R}
$$

Dimana: $\quad$ Loss $=$ rugi-rugi pada saluran $($ Watt $)$

$\mathrm{R}=$ resistansi saluran per fasa $(\mathrm{Ohm})$

$\mathrm{I}=$ arus yang mengalir per fasa (Ampere)

Nilai resistansi dari suatu penghantar merupakan penyebab utama rugi-rugi daya yang terjadi pada jaringang distribusi. Nilai resistansi dari suatu penghantar dipengaruhi oleh beberapa parameter. Berikut adalah persamaan resistansi penghantar :

$$
\mathrm{R}=\frac{p l}{\mathrm{~A}}
$$

Dimana: $\quad \mathrm{R}=$ Resistansi saluran $(\mathrm{Ohm})$

$P=$ resistivitas bahan penghantar (Ohm-meter)

$l=$ panjang penghantar

$\mathrm{A}=$ luas penampang $\left(\mathrm{m}^{2}\right)$

Studi Perbaikan Kualitas Tegangan dan Rugi-Rugi Daya Pada Penyulang Kulim dan Jelutung 


\section{METODOLOGI PENELITIAN}

\subsection{Data jaringan}

Jaringan yang digunakan pada penelitian ini merupakan jaringan distribusi $20 \mathrm{kV}$ pada gardu induk (GI) Auduri Telanaipura Cabang Jambi. Dimana penyulang yang disimulasikan adalah Penyulang Kulim dan Penyulang Jelutung. Beban trafo pada masing-masing gardu distribusi (GD) diasumsikan sebesar $65 \%$ dari kapasitas trafo.

Tabel 3.1 Kapasitas dan beban pada penyulang Kulim

\section{P. Kulim}

\begin{tabular}{|c|c|c|c|c|}
\hline No & Gardu & Kapasitas Trafo (kVA) & Beban Trafo & Load kVA \\
\hline 1 & JA 600 & 100 & $65 \%$ & 65 \\
\hline 2 & JA 818 & 160 & $65 \%$ & 104 \\
\hline 3 & JA 343 & 160 & $65 \%$ & 104 \\
\hline 4 & JAX 073 & 200 & $65 \%$ & 130 \\
\hline 5 & JAX 170 & 200 & $65 \%$ & 130 \\
\hline 6 & JAX 074 & 200 & $65 \%$ & 130 \\
\hline 7 & JA 165 & 200 & $65 \%$ & 130 \\
\hline 8 & JA 785 & 50 & $65 \%$ & 32,5 \\
\hline 9 & JA 543 & 50 & $65 \%$ & 32,5 \\
\hline 10 & JA 846 & 100 & $65 \%$ & 65 \\
\hline 11 & JA 743 & 100 & $65 \%$ & 65 \\
\hline 12 & JA 590 & 100 & $65 \%$ & 65 \\
\hline 13 & JA 542 & 100 & $65 \%$ & 65 \\
\hline 14 & JA 786 & 100 & $65 \%$ & 65 \\
\hline 15 & JA 735 & 50 & $65 \%$ & 32,5 \\
\hline 16 & JAX 139 & 25 & $65 \%$ & 16,25 \\
\hline 17 & JA 184 & 50 & $65 \%$ & 32,5 \\
\hline 18 & JA 672 & 160 & $65 \%$ & 104 \\
\hline 19 & JA 125 & 160 & $65 \%$ & 104 \\
\hline 20 & JA 172 & 100 & $65 \%$ & 65 \\
\hline 21 & JA 548 & 160 & $65 \%$ & 104 \\
\hline 22 & JA 140 & 50 & $65 \%$ & 32,5 \\
\hline 23 & JA 132 & 160 & $65 \%$ & 104 \\
\hline 24 & JA 141 & 200 & $65 \%$ & 130 \\
\hline 25 & JA 178 & 100 & $65 \%$ & 65 \\
\hline 26 & JA 551 & 160 & $65 \%$ & 104 \\
\hline 27 & JA 321 & 200 & $65 \%$ & 130 \\
\hline 28 & JA 653 & 100 & $65 \%$ & 65 \\
\hline 29 & JA 169 & 200 & $65 \%$ & 130 \\
\hline 30 & JA 540 & 100 & $65 \%$ & 65 \\
\hline 31 & JA 183 & 100 & $65 \%$ & 65 \\
\hline 32 & JA 139 & 160 & $65 \%$ & 104 \\
\hline 33 & JA 844 & 100 & $65 \%$ & 65 \\
\hline
\end{tabular}

Tabel 3.2 Kapasitas dan beban pada penyulang Jelutung

\section{P. Jelutung}

\begin{tabular}{|l|c|c|c|c|}
\hline No & Gardu & Kapasitas Trafo (kVA) & Beban Trafo & Load kVA \\
\hline 1 & JA 803 & 200 & $65 \%$ & 130 \\
\hline 2 & JA 223 & 100 & $65 \%$ & 65 \\
\hline 3 & JA 234 & 100 & $65 \%$ & 65 \\
\hline 4 & JA 245 & 200 & $65 \%$ & 130 \\
\hline 5 & JAX 143 & 200 & $65 \%$ & 130 \\
\hline 6 & JAX 142 & 160 & $65 \%$ & 104 \\
\hline 7 & JA 929 & 200 & $65 \%$ & 130 \\
\hline 8 & JA 932 & 50 & $65 \%$ & 32,5 \\
\hline 9 & JA 467 & 160 & $65 \%$ & 104 \\
\hline 10 & JA 233 & 100 & $65 \%$ & 65 \\
\hline 11 & JA 210 & 100 & $65 \%$ & 65 \\
\hline 12 & JA 636 & 100 & $65 \%$ & 65 \\
\hline 13 & JA 557 & 100 & $65 \%$ & 65 \\
\hline 14 & JA 040 & 100 & $65 \%$ & 65 \\
\hline 15 & JA 859 & 100 & $65 \%$ & 65 \\
\hline 16 & JA 847 & 100 & $65 \%$ & \\
\hline
\end{tabular}

Studi Perbaikan Kualitas Tegangan dan Rugi-Rugi Daya Pada Penyulang Kulim dan Jelutung Dengan Menggunakan Aplikasi Etap 12.6

(R.M. Eddy Suherman, Marliyus Sunarhati) 


\begin{tabular}{|l|l|l|l|c|}
\hline 17 & JA 733 & 160 & $65 \%$ & 104 \\
\hline 18 & JA 438 & 100 & $65 \%$ & 65 \\
\hline 19 & JA 623 & 100 & $65 \%$ & 65 \\
\hline 20 & JA 729 & 200 & $65 \%$ & 130 \\
\hline 21 & JA 684 & 100 & $65 \%$ & 65 \\
\hline 22 & JA 726 & 160 & $65 \%$ & 104 \\
\hline 23 & JA 123 & 200 & $65 \%$ & 130 \\
\hline 24 & JA 404 & 100 & $65 \%$ & 65 \\
\hline 25 & JA 845 & 100 & $65 \%$ & 104 \\
\hline 26 & JA 116 & 160 & $65 \%$ & 104 \\
\hline 27 & JA 654 & 160 & $65 \%$ & \\
\hline
\end{tabular}

Total panjang penyulang Kulim sebesar 40.010 m, sedangkan Penyulang Jelutung sebesar $9.142 \mathrm{~m}$.

\subsection{Perbaikan dengan penggantian kabel penyulang $20 \mathrm{kv}$}

Pada metode ini perbaikan kualitas tegangan dilakukan dengan mengganti kabel penyulang yang telah ada dengan kabel penyulang baru. Kabel penyulang yang akan digunakan untuk menggantikan kabel lama merupakan kabel penyulang yang nilai impedansinya lebih kecil. Kabel yang akan digunakan sebagai kabel pengganti merupakan kabel tipe XLPE (N2XSYBY/NA2SEBY) dengan luas penampang $300 \mathrm{~mm}^{2}$.

\subsubsection{Langkah-langkah perbaikan dengan penggantian kabel $20 \mathrm{kV}$}

Proses perbaikan akan dilakukan dengan dua langkah pengantian kabel, yaitu:

Pada percobaan yang pertama, penggantian kabel hanya dilakukan pada satu penyulang saja. Dimana kabel yang telah ada dingganti dengan kabel tipe XLPE $300 \mathrm{~mm}^{2}$. Setelah dilakukan penggantian kabel sepanjang satu penyulang, barulah dilakukan simulasi menggunakan perangkat lunak ETAP 12.6. Dari hasil simulasi tersebut akan didapatkan data berupa nilai tegangan pada masing-masing bus dan rugi-rugi daya yang terjadi pada system.

Untuk percobaan yang kedua, penggantian kabel dilakukan pada dua buah penyulang. Dimana kabel yang telah ada pada kedua penyulang tersebut diganti dengan kabel tipe EXLPE 300 $\mathrm{mm}^{2}$. Setelah dilakukan penggantian kabel pada kedua buah penyulang tersebut, kemudian dilakukan simulasi menggunakan perangkat lunak ETAP 12.6. Dari hasil simulasi inipun akan didapatkan data berupa nilai tegangan pada masing-masing bus dan juga rugi-rugi daya yang terjadi pada jaringan distribusi.

Dengan membandingkan data hasil simulasi dari kedua metode tersebut, akan diketahui metode yang paling optimal dalam memperbaiki kualitas tegangan pada jaringan distribusi. Metode yang paling optimal yang dapat memperbaiki nilai tegangan pada masing-masing bus semaksimal mungkin, serta dapat meminimalkan rugi-rugi daya yang terjadi pada jaringan distribusi.

\subsubsection{Uji keandalan penggantian kabel penyulang $20 \mathrm{kV}$}

Metode perbaikan yang paling optimal harus diuji keandalannya pada berbagai tingkat pembebanan. Tingkat pembebanan yang akan diberikan pada metode tersebut nilainya bervariasi, $65 \%$ dan 100\% dari beban puncak, sebelum dilakukan simulasi dalam perangkat lunak ETAP 12.6, masingmasing beban pada jaringan distribusi harus diatur terlebih dahulu sesuai dengan tingkat pembebanan yang diinginkan.

Dari hasil simulasi tersebut akan didapatkan data berupa nilai tegangan pada masing-masing bus pada berbagai tingkat pembebanan. Metode perbaikan yang tidak mengalami tegangan berlebih pada saat kondisi beban ringan $(65 \%)$ serta memberikan perbaikan tegangan yang optimal pada saat beban tinggi (100\%) merupakan metode perbaikan yang akan dipilih. 

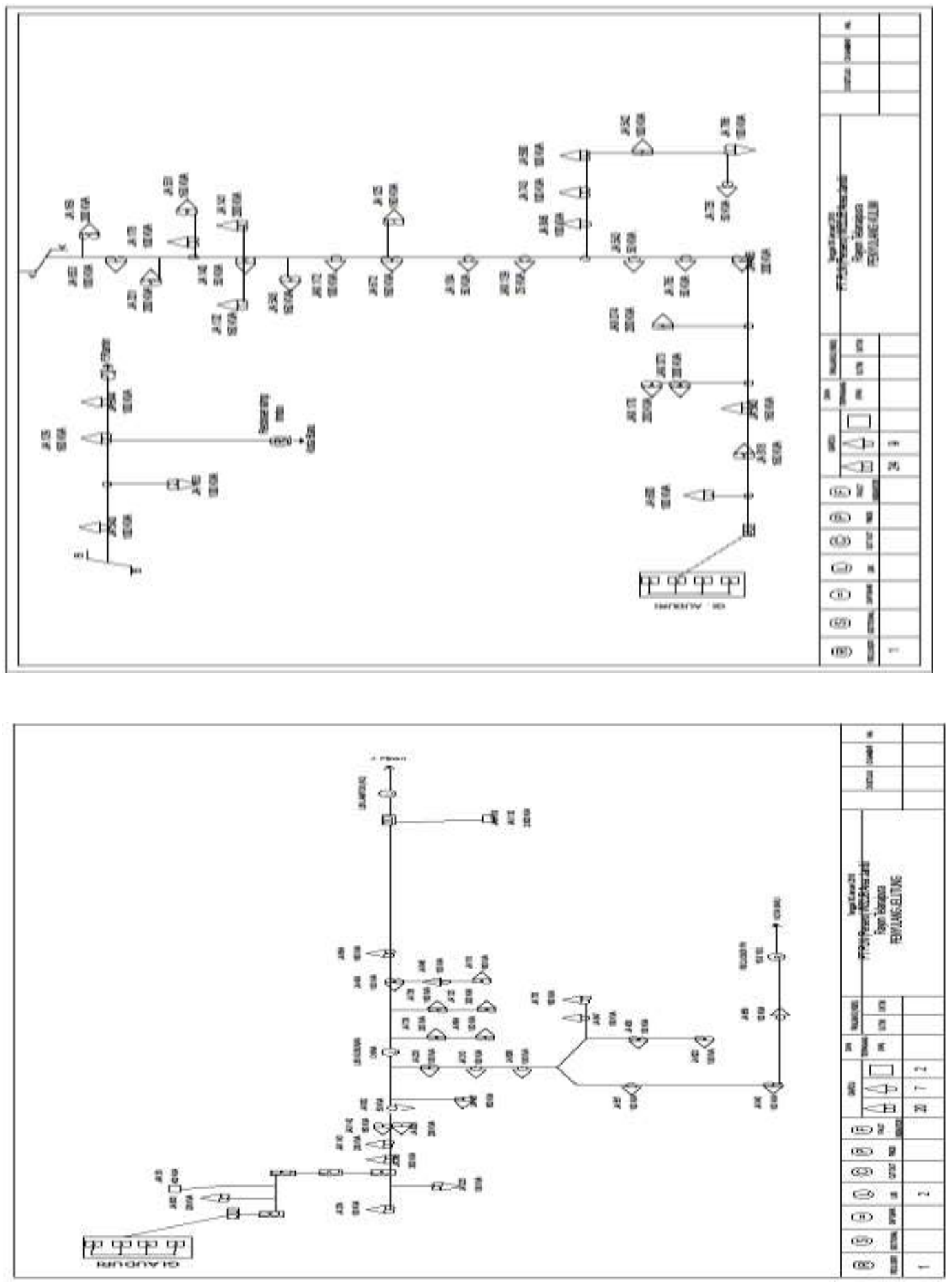

Gambar Diagram Satu Garis Penyulang Jelutung

Studi Perbaikan Kualitas Tegangan dan Rugi-Rugi Daya Pada Penyulang Kulim dan Jelutung Dengan Menggunakan Aplikasi Etap 12.6

(R.M. Eddy Suherman, Marliyus Sunarhati) 

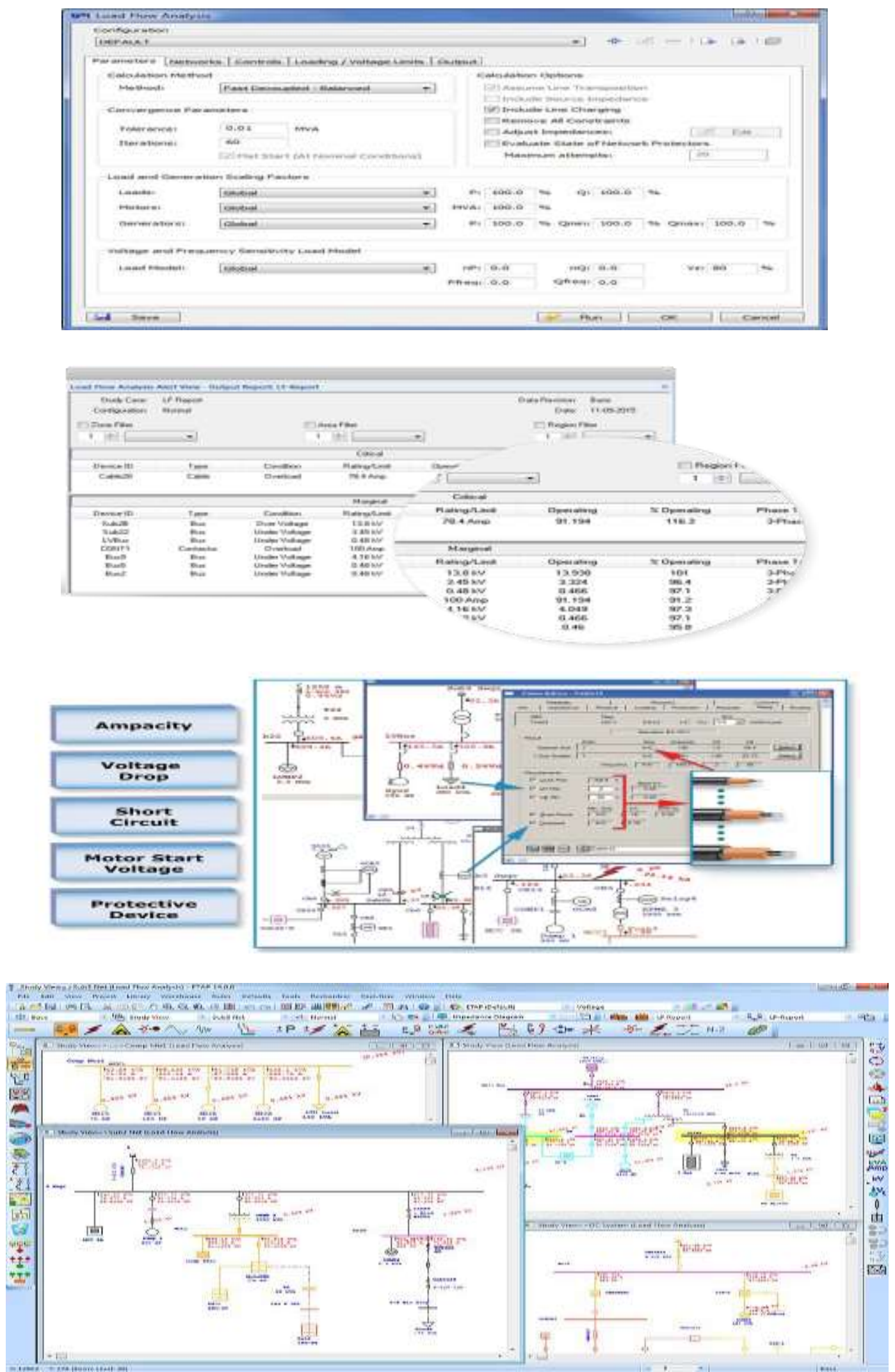

Gambar Program ETAP 12.6 untuk simulasi pada perhitungan pengantian kabel XLPE $300 \mathrm{~mm}^{2}$ Program ETAP 12.6

Studi Perbaikan Kualitas Tegangan dan Rugi-Rugi Daya Pada Penyulang Kulim dan Jelutung Dengan Menggunakan Aplikasi Etap 12.6 


\section{ANALISA DAN PERHITUNGAN}

\section{Hasil analisa perbaikan dengan penggantian kabel XLPE $300 \mathbf{~ m m}^{2}$}

Pada tabel tersebut diatas dapat dilihat, perbaikan menggunakan kabel ELPE $300 \mathrm{~mm}^{2}$ pada penyulang Kulim dan Jelutung menghasilkan pengurangan rugi-rugi daya dan rata-rata jatuh tegangan yang paling besar. Dimana rugi-rugi daya yang terjadi pada jaringang adalah $207,5 \mathrm{~kW}$ ( 5,51 \% lebih kecil dibandingkan kondisi awal jaringan). Rata-rata jatuh tegangan disisi tegangan menegah dan rendah penyulang Kulim adalah 0,129 \% dan 3,408 \%. Dan pada sisi tegangan menengah dan rendah pada penyulang Jelutung adalah $0,013 \%$ dan $3,53 \%$.

Tegangan terendah di sisi tegangan menengah dan rendah dari penyulang Kulim setelah perbaikan adalah $0 \%$ dan 2,7\% dari tegangan nominal. Sedangkan tegangan terendah di sisi tegangan menengah dan rendah dari penyulang Jelutung adalah $0 \%$ dan $0,01 \%$ dari tegangan nominal.

Tabel 4.9 Perbandingan Hasil Perbaikan

\begin{tabular}{|l|c|c|c|c|c|c|}
\hline Metode perbaikan & $\begin{array}{l}\text { Rugi-rugi } \\
\text { daya P. } \\
\text { Kulim } \\
(\mathrm{kW})\end{array}$ & $\begin{array}{l}\text { Rata-rata V } \\
\text { Jatuh di TM } \\
\text { P. Kulim } \\
(\%)\end{array}$ & $\begin{array}{l}\text { Rata-rata V } \\
\text { Jatuh di TR P. } \\
\text { Kulim }(\%)\end{array}$ & $\begin{array}{l}\text { Rugi-rugi } \\
\text { daya } \\
\text { Jelutung } \\
(\mathrm{kW})\end{array}$ & $\begin{array}{c}\text { Rata-rata V } \\
\text { Jatuh di TM } \\
\text { P. Jelutung } \\
(\%)\end{array}$ & $\begin{array}{c}\text { Rata-rata V } \\
\text { Jatuh di TR P. } \\
\text { Jelutung }(\%)\end{array}$ \\
\hline Nominal & & & & & & \\
\hline XLPE 240 mm2 Beban 65 \% & 63,4 & 0,086 & 2,28 & 33,4 & 0,008 & 2,32 \\
\hline XLPE 300 mm2 Beban 65\% & 57,4 & 0,083 & 2,25 & 33,1 & 0,008 & 2,32 \\
\hline XLPE 240 mm2 Beban 100\% & 142,2 & 0,133 & 3,43 & 77,4 & 0,014 & 3,53 \\
\hline XLPE 300 mm2 Beban 100\% & 130,9 & 0,129 & 3,4 & 76,6 & 0,013 & 3,53 \\
\hline
\end{tabular}

\section{PENUTUP}

Dari hasil simulasi dan analisa yang telah dilakukan, dapat diambil kesimpulan sebagai berikut :

1. Perbaikan penggantian kabel XLPE $300 \mathrm{~mm}^{2}$ pada penyulang Kulim dan Jelutung merupakan metode perbaikan optimal dan handal dalam memperbaiki jatuh tegangan dan rugi-rugi daya yang terjadi pada kedua penyulang tersebut.

2. Perbaikan dengan penggantian kabel pada penyulang Kulim dan Jelutung menghasilkan pengurangan rugi-rugi daya paling besar yaitu sebesar $0,133 \%$ dan 0,014

3. Metode penggantian kabel tersebut juga memperbaiki tegangan pada kedua penyulang. Dimana tegangan terendah di sisi tegangan menengah dan rendah dari penyulang Kulim setelah penggantian kabel adalah $0,83 \%$ dan $0,008 \%$ dari tegangan nominal. Sedangkan tegangan terendah di sisi tegangan menengah dan rendah dari penyulang Jelutung adalah $0,1333 \%$ dan $3,43 \%$ dari tegangan nominal.

\section{DAFTAR PUSTAKA}

1) JR, William D. Stevenson, "Elements of Power System Analysis, $4^{\mathrm{TH}}$ Edition”, McGraw-Hill, 1982

2) Weedy, B, M., Cory, B. J.," Electric Power system, $4^{\text {th }}$ Edition, John Wiley \& Sons, 1967.

3) Marsudi, Djiteng," Operasi sistem Tenaga Listrik", Edisi kedua, Graha Ilmu, Yogyakarta, 2006.

4) Chapman, Stephen J., "Electric Machinery and Power system Fundamental", McGraw=Hill, New York, 2002.

5) Murty, P, S, R, "Power system Operation and control", TATA McGraw-Hill, New Delhi, 1984.

6) Kundur, Prabha, "Power system Stability and Control", McGraw-Hill, California, 1993.

7) Taylor, Carson W.,"Power system Voltage Stability”, McGraw-Hill, Singapore, 1994. 